\title{
Forms and Figures of the Sensitive: The Question of Science and Technology
}

\author{
Anselmo Orlando Pinto \\ Post/Graduate Department at the Faculty of Ethics, Humanities and Legal Sciences of the University of Saint Thomas of Mozambique, \\ Maputo, Mozambique
}

Email address:

anselmoorlando@yahoo.com.br

\section{To cite this article:}

Anselmo Orlando Pinto. Forms and Figures of the Sensitive: The Question of Science and Technology. International Journal of Philosophy. Vol. 7, No. 4, 2019, pp. 135-140. doi: 10.11648/j.ijp.20190704.11

Received: July 19, 2019; Accepted: September 16, 2019; Published: October 14, 2019

\begin{abstract}
Figure is the idea one has of the world, whereas form is the totality of determinations, it is the essence in its phenomenal manifestation. Human knowledge takes three forms, that is, ordinary, scientific and philosophical. In the ordinary form men can have knowledge without recourse to particular wits; in scientific form knowledge is organized and disciplined and seeks to establish constant relations between phenomena, in the last instance, in the philosophical form knowledge has the characteristic of offering ultimate explanations to all phenomena. The split between science and philosophy that began in the seventeenth century with Descartes's dissociation between the thinking/self, the ego cogitans, and the material thing, the extended Res, creates a tragic problem in science: science is not known, does not have the self-reflective ability. This drama also concerns philosophy, which, no longer being empirically nourished, suffered the agony of the philosophy of nature and the failure of the philosophy of life; There was as much extralucidity in Husserl when he diagnosed the crisis of scientific knowledge as metaphysical delusion, stratospheric evasion in the idea of "transcendental ego." This study is articulated in three points 1) figures and forms of sensitive2) science, technique and technology and 3) Cultural meaning of technologies.
\end{abstract}

Keywords: Form, Figure, Knowledge, Science, Technique

\section{Introduction}

The question of science and technique is today subject of reflection in many areas; whatever the horizon, the best approach is one that more than talking about a separate science and technique, reflects on technoscience to indicate, those scientific processes that by their experimental nature act a technical moment and a cognitive moment, through a reciprocal influence, making it pure research and not separable from its application.

From 900 it is very relevant to speak of technoscience than separating science and technique [1]. After that, there will be several consequences of technoscience, it is enough to consider that the application without reflection and evaluation of technique and pure science can bring catastrophic results. The fear that such a situation arouses and that this does not happen, guides us to sociological, ethical and philosophical reflection in general.

Severe criticism has arisen in all environments of science and technique that is accused of having caused the loss of the fundamental values of the spirit (Scheler, Bernanos), of dehumanizing man by depriving him of freedom and the spirit of sociability. and of friendship (M. Buber, M. Heidegger), of having caused an irreparable devastation of the world, causing the energy crisis and the ecological emergencies (Munford, Russell, Marcuse, Moltman). A concept becomes scientific as it becomes technical, when it is accompanied by a technique of realization [2]. Cognitive development depends to a large extent on the integration of experience with technological instrumentalization. In fact, experimental science can be defined as a technoscience, that is, as a meeting place between the models of knowledge and those of know-how.

\section{Figures and Forms of the Sensitive}

In the conceptual perspective figure corresponds to various world views (weltanschauung); designates the fundamental forms that are specifications of such forms [3]. Form, on the other hand, is any subsistent (scholastic) substance. For Henri 
Bergson, form is a snapshot of a transition, an intermediate image from which real images approach. Hegel speaks of the form as the totality of determinations; as essence in its manifestation as a phenomenon. The sensible, therefore, that which can be perceived by the senses. In this sense the sensible is the object of knowledge.

Human knowledge takes three forms namely: ordinary, scientific, and philosophical. In ordinary form - all men can have knowledge without recourse to particular wits, without the force of systematization. It is therefore aesthetic / intuitive knowledge. The philosophical form, is a knowledge that aims to offer an ultimate explanation to all phenomena. And ultimately, the scientific form is organized and disciplined knowledge that seeks to establish constant relations between phenomena. It is a knowledge that deals with phenomena, hence it is based on empiricism.

\subsection{Ordinary Form - Aesthetic Knowledge}

The history of philosophical thought owes Aristotle the first systematic analysis of sensations and the recognition of their importance and necessity for the formation of knowledge. In Martin Heidegger, representation is the fundamental ontological act of the metaphysics of the existing [4]. The science of knowledge and presentation of the sensible is aesthetics, as inferior gnosisology [5] which is, however, far from being without difficulty.

Hungarian philosopher Georg Lukács considers that since Hegelian aesthetics, there has been no other philosopher attempting to systematize the essence of aesthetics. Nevertheless, the Hungarian author questions the grounding based on philosophical idealism, breaking with the mechanical and hierarchical definitions proposed by Hegel [6].

Authors who have come relatively close to some clarity about the authentic problems of aesthetics are of extraordinary importance. On the other hand, often seemingly distant thoughts, ethical or philosophical ideas, for example, are very important for understanding aesthetic phenomena. Since human life is a contradictory unitary reality and is found in social interrelationships, the essence of aesthetics cannot be understood, even in a rough way, if it is not in constant comparison with other modes of human reactions.

Any connoisseur of Hegel understands that in his system art is correlated with intuition, religion with representation, and philosophy with concept. In the young Schelling (17751854) this hierarchy would not change much, even though he gave art a place contrary to that defined by Hegel. The idealistic confusion has given rise to pseudo-problems that since Plato (348-347 $\mathrm{BC})$ have made it difficult to methodologically understand all aesthetics. These deformations of the relationship between art and nature, religion, science and other complexes produce problems of the forms of objectivity.

In complete contrast, materialist philosophy holds that the forms of objectivity, the categories corresponding to objects and their relationships, are not the products of a creative consciousness, as idealism does. For materialism, there is an objective reality in them that exists independently of consciousness. Therefore, all the divergences and contradictions that characterize the different types of reflex of the real develop within the framework of this materially and formally unitary reality. Art is a peculiar mode of manifestation of the reflection of reality, a mode that is but a genre of man's universal relations with reality. One of the central and decisive theses of this aesthetic conception is the defense that "all forms of reflection always reproduce the same objective reality". In academic environments, arts subjects such as art and design, music, drama and dance are often associated with creativity and innovation. A broad and balanced curriculum recognizes that arts can help students to develop their own creative voice and creative thinking skills [7].

The great theorists of the aesthetic phenomenon agree to consider art as a product of fantasy. For GiambattistaVico art is a fundamental and original way of expressing, on the part of man, a certain phase of its development [8]. Already for Kant, art is the result of feeling, which, in the work of art, perceives and expresses the universal in the particular, the intelligible in the sensitive, thenoumenon in the phenomenon. Art is the liberation of an idea, of an intuition.

\subsection{Philosophical Form - Intellectual Knowledge}

Man has the idea of goodness, virtue, work, society. They are all ideas that do not refer to anything material or concrete, but to something universal and abstract. With intellectual knowledge man formulates judgments, universal propositions, general laws. A very important step of intellectual knowledge is the scope of science, which will be further object of our study.

Source of Intellectual Knowledge-for the Platonists (Plato, Augustine, Descartes, Leibnitz, Malebranche, Rosmini, among others) intellectual knowledge is received from a higher source. This thesis derives, first, from the desire to give a secure foundation, an absolute guarantee, capable of dispelling any doubt to human knowledge. Secondly, certain properties, such as the absolute necessity, immutability, universality that some of our knowledge present, which the finite and changing human mind does not seem able to secure.

Aristotle, Kant, and all his other disciples did not find the Platonic foundation of the origin of intellectual knowledge plausible. Modernly, the main reason that distances us from the Platonists is the secularized view of reality, which prevents us from postulating the intervention of extramundane beings to explain events in this world. Moreover, our knowledge is not endowed with that character of absolute certainty, immutability, eternity ascribed to him by Plato. Today we are more than aware of the limits of our knowledge, it is in all cases finite and changeable, partial and relative and always carries a diversity of opinions. Universality, intentionality, worldliness, perspective, personalisticity, historicity are properties of intellectual knowledge. 


\subsection{Scientific Form - Science and Technique}

The question of science and technique develops along an unfinished course. The genesis of the problem of science and technique goes back to the ancient times of philosophical thought of unquestionable importance for the history of mankind, as is the case with Greek thought. The original conception of science and technique has its roots in Greek thought, but it is the last century that has rekindled the debate about science and technique. The past century has witnessed an unseen evolution of science and technology, with them a constellation of problems. In fact, one analysis argues that the evolution of science, the technological invention, the application of technique improves the quality of life of humanity. However, a value analysis makes clear from the outset the danger that unbridled evolution of science may pose.

Today, science and technique bring in complex questions. That are on the table of the debates of science and technique and there are problems of its evolution, from the disproportionate theorized in modern times to the real problems of our day, such as the clamorous wars, cloning, artificial breeding, experimentation on humans, euthanasia, attempts to improve human beings, environmental ecological problems, etc.

These problems exist and will exist because they pose a challenge to both intelligence and the will of man. And until when they will exist, all attempts to reflect on science and technique as forms and figures of the sensible will be useful. Indeed, the unbridled evolution of episteme today necessitates a philosophical accompaniment.

This reflection reconstructs the foundations of thought around science and technique. Reconstruction is a nod to the importance of the origins of the concepts in question. Although the origins are important, the synthesis of thought on science and technique is nowadays. A news that watches the evolution of technique and science as a simultaneous and inseparable event, therefore, technoscience.

Science has as its object the true. In classical metaphysics one speaks of the true, that is, the truth, as the adequacy of the intellect to the reality of things; while the technique $\tau \varepsilon \chi \eta \varepsilon$ - deals with the useful. For Aristotle, being has multiple meanings, among which eidos (essence) and ousia (substance or actual existence); Thus, the conception of being as an effective presence is emphasized [9]. The technification of the world is the realization of the idea that man, with his rationality, thinks the being of things as dependent upon himself and reducing himself to it.

The scientific spirit is unable to think so much that scientific knowledge is a reflection of the real. Does this knowledge, after all, not contain in itself the empirical proof (data verified by different observations-experiments) and the logical proof (coherence of theories)? From that point on, the objective truth of science escapes every scientific view, since it is that very look. What is elucidative does not need to be elucidated [10]. Scientific theories give form, order, and organization to the verified data on which they are based, and so are systems of ideas, constructs of the spirit that apply to the data to suit them.

In the Vienna Circle, a group of scientists, logicians, and mathematicians had in common the total view for the arbitrary of philosophy and metaphysics. They wanted philosophy, thought, to reflect the image of science, meaning meaningful statements, and to be based on what is observable and verifiable.

For them, science was the model and they raised the following problem: "what is science?" [11]. They wanted to study the model and the study of that model led to a series of misadventures and disappointments: they believed they had found a foundation and it failed.

One such failure happened, for example, on the plane of logic (or mathematical logic) with Godel'sundecidability theorem. Another failure was Wittgenstein's resignation and disillusionment. But another scientist and philosopher, Whitehead, Russell's collaborator, had already seen that science is even more changeable than theology - these are its concepts. However, science is not only a body of knowledge to be learned and understood, it represents a powerful method in identifying and solving problems with a significant creative component [12]. Well-planned, structured enquiry is fundamental to science teaching as it reflects the scientific method: curiosity based on existing knowledge, hypothesis formulation, systematic observation, measurement and experimentation leading to new insights [13].

The data on which scientific theories are based is objective, objective by verification, falsification, and that is absolutely unquestionable. What can be rightly contested is that a theory is objective. No, a theory is not objective; A theory is not a reflection of reality; A theory is a construction of the mind, a logical-mathematical construction that allows us to answer certain questions we ask the world (Schelling), the reality.

The split between science and philosophy that began in the seventeenth century with Descartes's dissociation between the thinking self, the ego cogitans, and the material thing, the extended Res, creates a tragic problem in science: science is not known; does not have the self-reflecting ability. This drama also concerns philosophy, which, no longer being empirically nourished, suffered the agony of the philosophy of nature and the failure of the philosophy of life; There was as much extralucidity in Husserl when he diagnosed the crisis of scientific knowledge as metaphysical delusion, stratospheric evasion in the idea of "transcendental ego." Thus philosophy is powerless to fertilize science, which is itself powerless to conceive.

From Kuhn, philosophy becomes aware of the importance of the social dimension and the historical root of science, while inaugurating an interdisciplinary style that tends to dissolve the classic boundaries between academic specialties [9].

Rosemari and Walter quoting Edgar Morin consider that with the construction of a new science -technosciencescientists have lost authority, and it has been concentrated in the hands of industrialists and state authorities that fund 
scientific research, there is an extraordinary relationship between research and power. They add that it is necessary to think that technoscience leads to anonymous knowledge that is no longer made to obey the function that has been that of knowledge throughout the history of humanity, that of being incorporated into human consciousness, minds and lives.

The new scientific knowledge is made to be deposited in the databases and to be used with the means and according to the decisions of the powers, that is, scientists can no longer control and verify all the knowledge produced today. In addition, the research is in the technobureaucratic institutions of society. Therefore, the technobureaucratic administration together with the hyperspecialization of labor produces widespread irresponsibility. Thus we can say that we are living in a period when the separation of ethical and scientific problems can compromise life if we lose sight of the human character of scientific and technological development.

\section{Cultural Meaning of Technologies}

Today the cultural environment in which we live is dominated by technology [14]. Human identity itself cannot be established without considering the environmental context - this relationship with nature operates through the mediation of technosciences, that is, the complex practical-theoretical system that is a characteristic element of modern man [15].

Its pervasive influence on our culture would not be intelligible if one understood only technique as hardware. The culture of a society determines the form and content of technological development. But technology plays an important role in people's lives and produces a view of the world and attitudes; creates new needs and values, stimulates further technological developments.

Social transformations that result from the technoscientific culture, namely:

The social - this is no longer defined as what binds humans, but as that which binds or associates divisions of entities which are attributed or not human and superhuman characteristics.

The sciences - these are not loaded with knowledge, but a work of representing nonhumans.

Politics - this is no longer defined as the measure or decision based on the facts and measures offered by the sciences, but as an assembly of all the spokespersons of the communities.

The moral - this is no longer defined by the limits that a transcendental knowledge about humans would demand not to exceed, but by a scrupulous accompaniment of the experience lived by the collective. Therefore, moral and ethical issues must be taken into account, as relevant by all. The most visible ethical issues are raised in the context of genetics and biotechnology, where respect for life is of major public concern. However, ethical issues emerge also in other areas of science and research, including respect for privacy in the use of information technology and obligations concerning the environment and climate change. In the social sciences, ethical issues are raised when sensitive issues such as fertility, ethnicity and religion are the subject of research, and the conduct of socio-economic research on human subjects should also respect ethical standards. Research ethics as precautionary governance of science and technology is not likely to take on the negative and individual-centred focus of the ethics of scientific misconduct. There may be case of blame and guilt, but more often there will rather be genuine uncertainty and a need for creative approaches to achieve the good rather than blame what is bad [16]. Law or theory- as Bhattcherjee says it is explanation of natural or social behavior, event or phenomenon and it should explain why things happen, rather than just describe or predict [17]; this is no longer the right of men in society, but of men and things in associations, collectively and in exchange of properties and qualifications, the right of humans has been replaced by a true right of things. Education -scientific and technical knowledge is essential for the knowledge-based society, and should be part of the basic skills of all citizens. A strong pool of scientist is needed to contribute to economic growth and social development. Increasing the attractiveness of science, mathematics and technology, and for careers in these areas, especially amongst the young, is a priority. Key actions focus on promoting science and technology in all levels of education, improving the ways in which science and technology are taught, and retaining the enthusiasm and opportunities for personal development of trained scientists in the private and public sectors [18]. To support the development of science literacy, school programs must provide a foundation of learning experiences that address critical aspects of science and its application. This critical areas provide general direction for the program and identify components of its structure [19].

\subsection{Science, Technique and Technology}

As was pointed out in the introduction of this work, in recent years, from the last century, science, technique and technology go hand in hand. Alternatively, science and technique are inextricably linked - the production of theoretical knowledge is no longer separate from its application, and the two practices offer each other tools and means for progress.

The concept of technology cuts across many disciplines: an engineer can look at the concept from an instrument perspective, for an economist technology symbolizes a mechanism for minimizing costs and maximizing benefits, for an anthropologist it is a cultural concept and for a sociologist represents a symbol of social change. The technique is therefore a multifaceted reality.

According to $\mathrm{H}$. Schelsky, one can distinguish between techniques of production (which produce real goods), techniques of organization (which regulate social relations with the help of the social sciences) and finally, human techniques (which shape psychic and cultural life).

Technology is the possibility to make a speech, to create knowledge about technique and is affirmed in the always strict relationship between technique and science - 
technoscience, a relationship that indicates two dimensions of knowledge that are indistinguishable, one is a condition of the existence of the other. Thus it is evident that technology acts not only on nature and on things, but on man himself, on society and its structures.

The epistemological model that marks the beginning of contemporary technological culture attributes to the feasible the connotation of truth. In other words - a speculative model that recognizes the truth of reality (intelligibility belongs to the real and is not the product of human cognitive activity. Therefore, it is progressively constituting an operative model that considers that it can guarantee value to knowledge only where man does) something buildable and buildable).

When the technique is simple availability of the instrument, this is not yet a life system, even though it is important for life; social life is in any case obliged to follow the steps that technology draws. It is not, however, a technological determinism - the macrosystem itself is a socio-technical fact. Technology elaborates projects that are projections of images of society and its demands.

\subsection{Continuity or Discontinuity with Yesterday's Technique}

Is there any continuity between today's technological systems and the techniques of the past? Modern technique is a process and a company, while that precedent is an achievement and a state. The difference between the two is fundamental. In the postmodern technique we find ourselves facing a situation oriented towards the attainment of a balance: there are profound occasional transformations, but the tendency is to reach a point of stability between the means and the instruments used, on the one hand, and on the other, requirements and recognized purposes. The central point of the technological domain is the idea of constant progress, where the successive step is always better than the previous one.

The fundamental difference between ancient technology and modern technology is that now technique is no longer commensurate with a precise and well-defined objective, such as that of responding to a determined need [10]. In the past technique was oriented toward a definite end, it answered a well-defined need - the work of technique was the ability to pass a thing of nonbeing into being. Technique (for the reasons of truth) calls into existence what cannot be produced by itself.

Technique as skill is linked to cognitive virtue relative to what can be brought to the surface of nature in the way it is to be produced. In modern technique, according to Romano Guardini, man loses his organic relation to reality.

\section{Conclusion}

This study aimed to show the articulation between philosophical thought, science and technique. Philosophy, as a body of human knowledge that deals with the inquiry into ultimate causes, is fundamentally called upon to reflect and evaluate technical-scientific procedures so that they are essentially an expression of the greatness of man and the meeting place between knowledge and action. Currently technical and scientific knowledge is completely different from the contemplative and discursive knowledge that dictates the meaning of the world, where reason, nature and freedom constitute a common ground, not directly related to effective action. Technique is that which favored human freedom, as it provided the means for action. Modern science has marked the decline of this way of knowing. Scientific knowledge has become an increasingly technical and separate product of natural experience, displacing philosophy as a discourse of truth. Technoscience appears as a dynamic vector of contemporary material culture, which is branched out by the laboratory, the factory, the environment, and our homes. Given that science and technology are elements of a cultural order, it is therefore appropriate and necessary to project the forms and figures of the sensible more objectively. Finally, it is necessary to perpetuate a continuous reflection on science and technology, thus giving it that intelligibility that enables it to be a manifestation of man and his aspirations for development.

\section{Acknowledgements}

This article is inspired by the discussions and reflections I had in March 2018 with the students of the master's degree program in philosophy on the question of science and technique.

\section{References}

[1] BACHELARD, G (2005). The formation of the scientific spirit. Contribution to a psychoanalysis of knowledge. Counterpoint Publisher, Rio de Janeiro.

[2] ABBAgnANO, N (2007). Philosophy Dictionary, Ed. Magazine, Lisbon.

[3] MONDIN, B (2006). Philosophical Anthropology. ESD, Bologna.

[4] TOLLE, O (2007). Aesthetic light: science of the Baumgarten sensitive between art and illumination (Dissertation). USP, Sao Paulo.

[5] DOS SANTOS D, COSTA F (2012). "Art as Proof of Human Immanence: A Dialogue with Lukács's Prologue to Aesthetics I". In José Albio Saleswoman -Dinamara Garcia Feldens (Org). Art and philosophy in the mediation of formative experiences. UECE Publishing House, Fortaleza.

[6] MONDIN B (1980). The man, who is he? Paulus, Sao Paulo.

[7] COCCO R (2006). "The Question of Technique in Martin Heidegger”. Controversy Magazine. Volume 2. $\mathrm{n}^{\circ} 1$.

[8] MORIN, E (2005). Science with consciousness. Bertrand Brazil, Rio de Janeiro.

[9] SILVEIRA F, BAZZO A (s/a). "Science and Technology: Transforming the Relationship of Human Being with the World". In Technology and Civilization, Paraná. 
[10] MANZONI, G (2004). The technology of the back. Queriniana, Brescia.

[11] Science Foundation Ireland (2015). An analysis of the Irish Public-s perceptions and awareness of STEM in Society. Dublin. Available at: https://www.sfi.ie/resources/SFIScience-in-Ireland-Barometer.pdf

[12] Innovation and creativity - Cambridge International. Available at: https://www.cambridgeinternational.org/Images/426483chapter-4-innovation-and-creativity.pdf

[13] National Institutes of Health (2018). Doing Science: The process of Inquiry. Available at: http://www.uwyo.edu/scienceposse/resources/nih_doingscience.pdf

[14] Department of Education \& Communities (2015). Guide to Application Writing for Classroom Teacher Positions. Available at: https://www.teach.nsw.edu.au/documents/app_guide.pdf

[15] OECD (2016). Measuring Science, Technology and Innovation. Available at: https://www.oecd.org/sti/STI-StatsBrochure.pdf
[16] National Committees for Research Ethics in Norway (2009). Risk and Uncertainty as a research Ethics Challenge. Norway. Available

https://www.etikkom.no/Aktuelt/publikasjoner/Risk-andUncertainty---as-a-Research-Ethics-Challenge

[17] BHATTCHERJEE, A (2012). Social Science Research> Principles, Methods, and Practices. USF, USA. Available at: https://scholarcommons.usf.edu/cgi/viewcontent.cgi?article=1 002\&context $=$ oa_textbooks

[18] European Commission (2007). Integrating science in society issues in scientific research. Available at: $\mathrm{http} / / / \mathrm{ec}$.europa.eu/research/sciencesociety/document_library/pdf_06/integrating-sis-issues-inresearch-main-findings_en.pdf

[19] Alberta Education (2014). Science Grades 7/8/9. Program of studies. Available at: https://education.alberta.ca/media/3069389/pos_science_7_9.p df 